\title{
Investigation and Research on Status of Mental Health of 1091 Students in Changchun
}

\author{
Sun Li \\ Jilin Agricultural University, \\ Changchun 130118,286578048@qq.com
}

Keywords: mental health,Middle school students,Middle school students' mental health scale.

\begin{abstract}
Purpose: In order to provide a scientific basis for students' mental health education in middle school, the author investigates the students' mental health status in middle school of Changchun. Methods: The questionnaire survey was conducted among 1091 middle school students in Changchun with the help of the Chinese middle school students' mental health scale. Results: 1 . Scores of urban middle school students were remarkably higher than rural students $(\mathrm{P}<0.001$, $\mathrm{t}=4$.182); 2. Among the status of middle school students from different family types in Changchun, it was found that mental health of middle school students' who live with their parents was much better than the left-behind children and students who were from the single parent family $(\mathrm{P}<0.001, \mathrm{t}=9.15)$.
\end{abstract}

\section{Introduction}

The investigation of 1091 high school students in Changchun was launched to understand the mental health status of middle school students. This study aimed to provide reference for the implementation of school mental health education.

\section{Object and methods}

2.1 Object. 1200 questionnaires were granted in Changchun, and 1091 effective questionnaires were recycled with the stratified sampling method. The effective questionnaire recovery rate was 90.9\%.Among them, in middle school, 116 students were the first grade with the average age of 13.4 years old;172 students were grade two with the average age of 14.6 years old; 107students were grade three with the average age of 15.6 years old. In high school, there were 284 students from grade one, 277 students from grade two, and 135 students from grade three, with the average age of 16.7, 17.9, and 18.9 yeas of old respectively.Among the effective samples, there were 391 urban students and 700 rural students.

2.2 The middle school student mental health scale (MSSMHS) was adopted in this research. It will show a good reliability if the scale of the retest reliability is between $0.716 \sim 0.905$, the homogeneity reliability is between $0.6501 \sim 0.8577$, and the reliability is between $0.6341 \sim 0.8400$. It will have a good structure validity if the correlations of scale scores and the subscales, and the correlation among each sbuscales were between $0.7652 \sim 0.8726$ and $0.4027 \sim 0.7587$ respectively. This scale is composed of 60 items, and a total of 10 subscales, namely force, paranoia, hostility and interpersonal sensitivity, depression, anxiety, learning pressure, maladjustment, emotional volatility, psychological imbalance. The scale has the score system of 5 levels[1].

Students filled in the questionnaires in accordance with the unified instructions independently, including the information about their personal background, age, gender, grade, family status, home address, etc.

\section{3 data processing}

Data were analyzed by SPSS17.0 software for statistical analysis, which mainly included the statistical methods, such as t test and $\mathrm{F}$ test. 。 


\section{Results}

Table 1. Mental health status of middle school students in Changchun

\begin{tabular}{ccc}
\hline Factor & M \pm sd & $\begin{array}{c}\text { Number of positive } \\
\text { items(percentage) }\end{array}$ \\
\hline Force & $2.23 \pm 0.60$ & $741(67.9)$ \\
Paranoia & $1.84 \pm 0.67$ & $406(37.2)$ \\
Hostility & $1.77 \pm 0.70$ & $373(34.2)$ \\
Interpersonal sensitivity & $2.06 \pm 0.71$ & $582(53.3)$ \\
Depression & $1.88 \pm 0.69$ & $453(41.5)$ \\
Anxiety & $2.08 \pm 0.83$ & $545(50.0)$ \\
Learning pressure & $2.10 \pm 0.82$ & $459(42.1)$ \\
Maladjustment & $1.89 \pm 0.64$ & $473(43.4)$ \\
Emotional volatility & $2.12 \pm 0.72$ & $618(56.6)$ \\
Psychological imbalance & $1.82 \pm 0.64$ & $405(37.1)$ \\
Overall & $1.98 \pm 0.55$ & $464(42.5)$
\end{tabular}

3.1 Among 1091 subjects of middle school students in Changchun, the number of positive items was $464,42.5 \%$ of the overall.Total equalization was $1.98+/-0.55$, which was within the normal range.

Table 2. Comparison on mental health condition between rural and urban middle school students of

\begin{tabular}{cccc}
\hline Factor & Rural N=700 & Urban N=391 & T- value \\
\hline Force & $2.23 \pm 0.59$ & $2.23 \pm 0.62$ & -0.516 \\
Paranoia & $1.79 \pm 0.63$ & $1.91 \pm 0.74$ & $2.702 * *$ \\
Hostility & $1.70 \pm 0.64$ & $1.91 \pm 0.78$ & $4.489 * * *$ \\
Interpersonal sensitivity & $2.02 \pm 0.69$ & $2.13 \pm 0.74$ & $2.333 *$ \\
Depression & $1.82 \pm 0.65$ & $1.97 \pm 0.76$ & $3.199 * *$ \\
Anxiety & $2.01 \pm 0.78$ & $2.22 \pm 0.90$ & $3.833 * * *$ \\
Learning pressure & $2.01 \pm 0.77$ & $2.24 \pm 0.90$ & $4.286 * * *$ \\
Maladjustment & $1.84 \pm 0.60$ & $1.99 \pm 0.70$ & $3.548 * * *$ \\
Emotional volatility & $2.05 \pm 0.68$ & $2.26 \pm 0.76$ & $4.504 * * *$ \\
Psychological imbalance & $1.78 \pm 0.62$ & $1.89 \pm 0.68$ & $2.911 * *$ \\
& & & \\
Overall & $1.93 \pm 0.52$ & $2.08 \pm 0.59$ & $4.182 * * *$
\end{tabular}

Changchun ( $\mathrm{M} \pm \mathrm{sd})$.

Annotation: * $\mathrm{P}<0.05, * * \mathrm{P}<0.01, * * * \mathrm{P}<0.001$

3.2 Comparison on mental health condition between rural and urban middle school students of Changchun. It was found that the total score and score of each factor of the urban middle school students were higher than that of the rural middle school students. Total score and all the factors except force factor had statistic significance. Among them, the status of sensitive interpersonal relationship of urban middle school students was significantly higher than rural students $(\mathrm{P}<0.05)$; on the factors of paranoid, depression and psychological unbalance, status of urban middle school students were significantly higher than rural students $(\mathrm{P}<0.01)$; when it comes to the factors of total split, hostility, anxiety, learning pressure, maladjustment and emotional volatility, the status of urban middle school students were significantly higher than that of rural middle school students $(\mathrm{P}<$ 0.001)。(see table 2) 
Table3. Middle school students of different family types of Changchun (M \pm sd)

\begin{tabular}{|c|c|c|c|c|c|}
\hline item & $\begin{array}{l}1 \text { Living } \\
\text { with their } \\
\text { parents } \\
(\mathrm{N}=851)\end{array}$ & $\begin{array}{l}2 \text { Single } \\
\text { parent } \\
\text { families } \\
(\mathrm{N}=81)\end{array}$ & $\begin{array}{l}3 \text { Left-behind } \\
\text { children } \\
(\mathrm{N}=64)\end{array}$ & $\begin{array}{c}4 \text { Other } \\
\text { situations } \\
(\mathrm{N}=95)\end{array}$ & F \\
\hline Force & $2.20 \pm 0.59$ & $2.31 \pm 0.61$ & $2.42 \pm 0.59$ & $2.30 \pm 0.66$ & $3.79 *$ \\
\hline Paranoia & $1.78 \pm 0.64$ & $2.13 \pm 0.84$ & $1.99 \pm 0.67$ & $1.99 \pm 0.69$ & $10.50 * * *$ \\
\hline Hostility & $1.72 \pm 0.67$ & $2.00 \pm 0.82$ & $1.89 \pm 0.71$ & $1.96 \pm 0.77$ & $7.55 * * *$ \\
\hline $\begin{array}{c}\text { Inter- } \\
\text { personal } \\
\text { sensitivity }\end{array}$ & $2.00 \pm 0.69$ & $2.34 \pm 0.81$ & $2.89 \pm 0.65$ & $2.21 \pm 0.69$ & $10.09 * * *$ \\
\hline Depression & $1.82 \pm 0.67$ & $2.18 \pm 0.85$ & $1.99 \pm 0.67$ & $2.00 \pm 0.66$ & $8.53 * * *$ \\
\hline Anxiety & $2.03 \pm 0.82$ & $2.39 \pm 0.98$ & $2.20 \pm 0.70$ & $2.24 \pm 0.77$ & $6.77 * * *$ \\
\hline $\begin{array}{l}\text { Learning } \\
\text { pressure }\end{array}$ & $2.06 \pm 0.81$ & $2.16 \pm 0.83$ & $2.25 \pm 0.90$ & $2.21 \pm 0.86$ & 1.96 \\
\hline $\begin{array}{c}\text { Mal- } \\
\text { adjustment }\end{array}$ & $1.84 \pm 0.62$ & $2.09 \pm 0.74$ & $1.95 \pm 0.60$ & $2.12 \pm 0.69$ & $8.55 * * *$ \\
\hline $\begin{array}{c}\text { Emotional } \\
\text { volatility }\end{array}$ & $2.09 \pm 0.70$ & $2.27 \pm 0.80$ & $2.30 \pm 0.72$ & $2.20 \pm 0.73$ & $3.50 *$ \\
\hline $\begin{array}{l}\text { Psychologic } \\
\text { al imbalance }\end{array}$ & $1.79 \pm 0.63$ & $1.96 \pm 0.73$ & $1.89 \pm 0.64$ & $1.91 \pm 0.68$ & $2.80 *$ \\
\hline Overall & $1.94 \pm 0.54$ & $2.18 \pm 0.64$ & $2.12 \pm 0.51$ & $1.98 \pm 0.55$ & $9.15 * * *$ \\
\hline
\end{tabular}

3.3 Comparison of different family types. After Comparing these four types of families, it was found that the difference on learning stress had no statistical significance; it had big difference on the three factors of force, emotional volatility, psychological imbalance $(\mathrm{P}<0.05)$; and it had extremely significant difference on factors of paranoia, hostility, interpersonal sensitivity, depression, anxiety, maladjustment $(\mathrm{P}<0.001)$. With further multiple comparison, it was found that: (1)between the group of living with their parents and the single parent family group, the latter group has a significantly higher score on paranoia, interpersonal sensitivity, depression,and the total score than that of the former group $(\mathrm{P}<0.01)$.The score of single-parent families was higher than that of living with their parents group in hostile, anxiety, maladjustment $(\mathrm{P}<0.05)$. (2)Between the group of Living with their parents and group of left-behind children. Score of left-behind children on interpersonal sensitivity factor was significant higher than the group of living with their parents group $(\mathrm{P}<0.01)$. On the force and total score, the status of left-behind children was significantly higher than living with their parents group $(\mathrm{P}<0.05)$. (3)The status of other groups were significantly higher than living with their parents group on maladjustment. On the paranoid, hostile interpersonal sensitivity and the total score, the status of other groups were significantly greater than living with their parents group ( $\mathrm{P}$ $<0.05)$. (4) Single-parent family group and left-behind children series did not exist significant differences. (5)Single-parent family group and other comparison group did not exist significant differences. (6)left-behind children series had no significant differences with other comparison groups.

\section{Discussion}

4.1Among 1091 subjects of middle school students in Changchun, the number of positive items was $464,42.5 \%$ of the overall. The results of this research is slightly lower than that of Ganzhou city and the research results of Henan province.Total average score were $1.98+/-0.55$, which was within normal range.Factors which were greater than 2 points were, in turn, force,emotional volatility, learning stress. Anxiety, and interpersonal sensitivity with the scores of $2.23+/-0.60,2.12+/-0.72$, $2.10+/-0.82,2.08+/-0.83$, and $2.06+/-0.71$ respectively. 
4.2 Comparison of mental health status of urban and rural middle school students in Changchun .It was found that the urban middle school students in the total score and each factor score were higher than that of the rural middle school students. Other factors, except for force factor, and total score had statistical significance.The mental health status of the rural middle school students was better than urban middle school students which was different from the research results from Zhang Yunsheng, Zhang Bairang, Gao Liuzhan, etc..

4.3 Comparison of different family types of middle school students in Changchun. It was found that the mental health status of the children who live with their parents was significantly better than those who were from the single parent family and the left-behind children, which was different from the inconsistent results of Yang Chunyu, He Jianguo, Luo Changming.

Middle school students from single-parent families had higher scores on total average score, paranoia, interpersonal sensitivity, depression, hostility, anxiety, maladjustment factor than those who live with their parents, and the differences were statistically significant. This result was similar with the research results of Ma Yingjiao. Educational function of the family was held by both parents. If the family had only one parent, it would reveal the lack of family education function. Children from single parent families, who had only one parent because of divorce, death or other unhappy family accident, would had a tremendous negative psychological impact on their heart. They had no sense of security in their family. Without warmth and spiritual pillar, they were more fragile than normal children. Facing with difficult reality, they had the strong desire to heal their hearts with warmth from family members. Therefore, it is very important for families, schools and society to pay more attention to the love of the mental health of children from common single family.

\section{Summary}

Mental health education of middle school students should be enhanced. Special attention should be paid to high school students, students from urban middle school students, students from single parent family, and the left-behind children. School, society and families should work together to improve the mental health level of middle school students.Middle school students are in adolescence, who are the high-risk groups of mental health problems.

\section{References}

[1] Wang Jisheng, Li Yan, He Ershi. Middle School Student Mental Health Scale of China and Its Standardization[J].Social Psychological Science,1997,(4):15-20.

[2]Yao Lifen, Liu Ying, Liu Minlan.Survey and Research on Students' Mental Health in Ganzhou Middle School [J].Jiang Xi Yaoyu scientific research, 2007 (6):60-62

[3]Xu Lifeng, Lu Weibin. Investigation and Analysis on Psychological Health Condition in Middle School Students [J].Journal of Guiyang Institute of Education (Social Science),2009(11):76-79

[4] Zhang Yunsheng, Zhang Bairang, Gao Liuzhan. Research on mental health status of middle school students in Kaifeng City [J].Journal of Henan University (Medical Science Edition),2002(1):71-74

[5] Yang Chunyu, He Jianguo, Luo Changming. Research on the Effects of Family Environment on the Junior Middle School Students' Mental Health[J]. China Journal of Health Psychology,2010(9):1127-1130

[6]Ma Yingjiao, Xu Jianguo, Cao Cong,etc. Mental Health Research on Single Parent Family of the Middle School Students [J] .Chinese Journal of School Health，2006， 27 (12) : 1063-1064.

[7]Zhong Lei, Yang Yingpng, Luo Yonggang. Investigation and Countermeasure of the Left-behind Children's Mental Health and Present Education Situation [ J ] Jinan Vocational College Journal, 2010 (1):76-79 
Author: Sun Li(1979- ), female, from Changchun Jilin Province, majored in mental health of college students. Telephone number: 13844105639 